\title{
TRADISI MITONI SEBAGAI PEREKAT SOSIAL BUDAYA MASYARAKAT JAWA
}

\author{
Yohanes Boanergis, Jacob Daan Engel, David Samiyono \\ Universitas Kristen Satya Wacana, Salatiga. \\ yohanes_boa@yahoo.com,jopie_engel@yahoo.com, \\ d_samiyono@yahoo.com
}

\begin{abstract}
The mitoni tradition is a Javanese cultural heritage that is still being held by Javanese people in the village of Tuntang, Tuntang District, Semarang District, Central Java until now. The mitoni ceremony is carried out in the seventh month of Javanese pregnancy. This study aims at examining the spiritual values of the mitoni tradition as socio-cultural "glue." This research was motivated by dangerous facts, namely the threat of disharmony in the social community. The method applied in this study is qualitative with a descriptive approach. Data collection techniques were used in-depth interviews and observations. Interviews were conducted by giving open questions to community leaders in the village of Tuntang. In this study, the sources of information were traditional leaders as representatives of the Tuntang village community. This research was tested as a socio-cultural adhesive in Tuntang village through spiritual values, namely: 1). Ngruwat sukerta. 2). Cecawis. 3). Sembada. 4). Panampi. 5). Wilujeng. 6). Ngrumat bumi. 7). Pitutur. 8). Rukun. 9). Pitulungan. These spiritual values are symbolic of Javanese ideology which is eschatological. This value serves to maintain social harmony. The results of this study are recommended for religious leaders and traditional leaders to apply this cultural approach, by making mitoni as a socio-cultural "glue."
\end{abstract}

Keywords: Cultural, Javanese, Mitoni, Selamatan, Society. 


\section{Pendahuluan}

Ungkapan "orang Jawa sudah kehilangan Jawanya, atau dalam bahasa Jawa disebut "wong jawa ora njawani" merupakan ungkapan yang ditujukan untuk orang Jawa yang melupakan tradisi budayanya sendiri. Menurut Saddhono dan Pramestuti, budaya Jawa merupakan suatu sistem yang menjadi pedoman bagi masyarakat Jawa dalam berperilaku dan bersikap. Hal ini dikarenakan budaya Jawa memiliki kearifan lokal yang berfungsi sebagai pendorong yang kuat dalam kehidupan masyarakat Jawa (Saddhono \& Pramestuti, 2018: 15).

Salah satu bentuk kebudayaan masyarakat Jawa yang mengandung unsur kearifan lokal adalah tradisi ritual seputar kelahiran. Beberapa tradisi ritual tersebut meliputi: upacara selamatan brokohan atau upacara setelah bayi lahir, sepasaran (lima hari), selapanan (tiga puluh lima hari), telunglapan (tiga bulan lima belas hari), mitoni (tujuh bulan), dan ngetahuni (setahun) (Risdianawati \& Hanif, 2015: 63). Fokus studi ini ialah meneliti tradisi mitoni sebagai perekat sosial budaya masyarakat Jawa di desa Tuntang. Tradisi merupakan kebiasaan dari aktifitas keagamaan yang telah berakar dalam kondisi sosial budaya (Nuha, 2016: 57). Mitoni adalah upacara yang dilakukan pada bulan ketujuh masa kehamilan masyarakat Jawa (Dagun, 2015: 664).

Studi mitoni sebelumnya ialah sebagai berikut: Rifa'i melihat mitoni dari sisi komunikasi yang terjadi di kalangan masyarakat (Rifa'i, 2017: 27). Mustaqim menemukan bahwa ritual mitoni yang dilakukan di tengah masyarakat sudah mengalami pergeseran, dari sisi makna maupun kualitas ritual (Mustaqim, 2017: 120).

Marliyana juga telah meneliti pelaksanaan mitoni meliputi; persiapan, upacara inti 
dan penutup (Marliyana dkk., 2016: 229).

Mitoni ditinjau dari sisi Islam oleh Adriana dan Buhori. Menurut Adriana, sebagian ulama melarang ritual mitoni, karena tidak ada syarî’at yang mendasarinya (Adriana, 2012: 246). Sementara itu, Buhori menjelaskan bahwa Islam cukup mengakomodir tradisi atau budaya yang berkembang di tengah-tengah masyarakat (Buhori, 2017: 245). Baihaqi meneliti karakteristik tradisi mitoni dengan menggunakan teori sastra lisan (Baihaqi, 2017: 136).

Studi mitoni sebelumnya tidak mengkaji nilai-nilai spiritual mitoni sebagai perekat sosial. Oleh sebab itu, studi ini akan mengkaji nilai-nilai spiritual dalam tahapan mitoni dan mengembangkannya sebagai perekat sosial masyarakat Jawa.

Penelitian ini dimotivasi oleh adanya fakta berbahaya, yaitu ancaman disharmoni sosial yang kerap terjadi di tengah masyarakat. Masyarakat
Indonesia pada umumnya sering mengalami konflik kekerasan. Hal ini terjadi dikarenakan kurangnya kesadaran masyarakat tentang ajaran budaya dan agama (Kurnialoh dkk., 2016: 201). Senada dengan itu, masyarakat dengan berbagai agama di dalamnya merupakan sebuah keadaan yang rawan akan konflik dan perpecahan. Isu agama adalah isu yang mudah sekali menyulut konflik dan perpecahan jika dibandingkan dengan isu-isu yang lain (Masduki, 2017: 14).

Disharmoni sosial dapat terjadi dikarenakan kurangnya pemahaman mengenai nilai agama dan budaya. Hal itu menyebabkan munculnya kecurigaan terhadap orang yang berbeda keyakinan, fanatisme agama yang sempit, dan sikap intoleransi. Masyarakat perlu menghayati nilai hidup bersama dalam praktek kehidupan agar harmoni sosial tetap terpelihara.

Berdasarkan latar belakang masalah tersebut, pertanyaan yang akan dijawab dalam penelitian ini 
ialah, bagaimana tradisi mitoni menjadi sarana perekat sosial budaya masyarakat Jawa?

\section{Metode Penelitian}

Penelitian ini menggunakan metode penelitian kualitatif dengan jenis penelitian lapangan. Metode penelitian kualitatif adalah metode penelitian yang berlandaskan pada filsafat postpositivisme atau enterpretif, dimana suatu realitas sosial dilihat sebagai sesuatu yang holistik, kompleks, dinamis dan penuh makna (Sugiyono, 2017: 8-10).

Pengumpulan data menggunakan metode wawancara dan melakukan observasi ketika terjadi mitoni. Wawancara dilakukan dengan memberikan pertanyaan terbuka kepada informan yang merupakan tokoh masyarakat desa Tuntang.

\section{Hasil Penelitian}

\section{Tradisi Mitoni Di Desa Tuntang}

Pelaksanaan mitoni tidak hanya untuk kelahiran anak pertama saja, melainkan untuk semua anak-anak (Wawancara Purlimah, 2018). Masyarakat Tuntang meyakini bahwa melalui ritual mitoni akan mendatangkan keselamatan bagi bayi dan ibu hamil. Keyakinan ini diwariskan kepada anak dan cucu. Hal ini sesuai dengan Boyd dan Richerson yang mengatakan bahwa budaya merupakan 'sistem warisan'. Budaya diperoleh dengan cara mengajar, meniru, dan bentuk pembelajaran sosial dari individu lain (Allen, 2015: 357).

\section{Makna Simbolis Tahapan Mitoni di Desa Tuntang \\ Berdasar hasil penelitian diperoleh penjelasan mengenai makna yang terdapat dalam simbol-simbol mitoni, sebagai berikut:}

\section{Makna Simbolis Tahapan}

\section{Siraman}

Siraman adalah tindakan untuk membersihkan tubuh. Upacara siraman menunjukkan tindakan simbolis yang bertujuan 
membersihkan kekotoran tubuh

ibu hamil dan membersihkan kekotoran jiwa. Siraman dalam istilah Jawa bertujuan untuk ngruwat sukerta atau "membuang kesialan".

Air siraman melambangkan penyucian dari kekotoran batiniah, sedangkan bunga tujuh rupa merupakan tindakan simbolis yang melambangkan keharuman (Wawancara Sutrisno, 2018). Air yang digunakan untuk siraman diambil dari tujuh sumber mata air, dalam bahasa Jawa disebut tuk pitu. Hal ini sebenarnya merupakan bentuk edukasi dari orang tua jaman dahulu, agar manusia memelihara bumi, dalam bahasa Jawa ngrumat bumi. Memelihara bumi dilakukan dengan menjaga sumber air di setiap desa supaya tidak kering (Wawancara Supratigya, 2018).

\section{Makna Simbolis Tahapan Ganti}

\section{Pakaian atau Ganti Busana}

Ibu hamil berganti pakaian sebanyak tujuh kali pada tahapan ngagem busana atau berganti pakaian. Setelah ibu hamil selesai mengenakan kain, dukun mitoni bertanya kepada tamu undangan yang hadir: "wis pantes durung?" atau "sudah pantas apa belum," lalu tamu undangan menjawab "durung" atau "belum". Demikian selanjutnya sampai pada kain terakhir yaitu kain lurik. Dukun mitoni bertanya "wis pantes durung?" maka tamu undangan menjawab "patut" atau pantas (Wawancara Sri Wiji, 2018).

Tahapan

ini menggambarkan persiapan psikologis untuk menghadapi persalinan yang rumit. Kata persiapan dalam istilah Jawa disebut cecawis.

\section{Makna Simbolis Tahapan}

\section{Brojolan}

Brojolan adalah acara melepaskan dua buah kelapa muda gading, dalam bahasa Jawa disebut cengkir gading. Kelapa tersebut diberi gambar tokoh wayang Kamajaya dan Kamaratih. Acara ini memiliki makna agar 
bayi dapat lahir dengan selamat, baik laki-laki ataupun perempuan (Wawancara Sutrisno, 2018). Hal senada juga disampaikan Purwadi, dikutip oleh Machmudah, pada saat brojolan diucapkan kata: "Wadon arep lanang arep waton slamet" Artinya, perempuan atau laki-laki semuanya diterima, yang penting selamat (Machmudah, 2016: 190).

Kata menerima dalam istilah Jawa disebut nampi. Penerimaan terhadap kehadiran anak menggambarkan spiritualitas batin orang Jawa, yaitu nrima atau berkenan menerima. Nrima menggambarkan watak yang sabar. Seseorang memiliki hati yang sabar sehingga tidak mudah menjadi emosi, mudah memaafkan dan penyayang (Sumodiningrat dan Wulandari, 2014: 271-272).

\section{Makna Simbolis Tahapan Kenduri}

Kenduri atau selamatan merupakan acara doa dan makan bersama yang menjadi tahap akhir ritual mitoni (Santosa, 2012: 5). Acara ini memiliki fungsi sosial terutama untuk merekatkan nilai solidaritas diantara anggota masyarakat (Humaeni, 2015: 176).

Sementara itu, di keluarga Supratigya, pelaksanaan mitoni dimodifikasi menggunakan perpaduan antara tradisi Jawa dengan tata cara modern. Mitoni diadakan dalam bentuk kenduri yang dipimpin oleh tokoh masyarakat

(Wawancara Supratigya, 2018).

Hidangan kenduri mitoni berupa tumpeng rombyong, nasi bundar tujuh atau sega golong pitu, cabe merah, ikan teri dan jenang procot. Tumpeng dilengkapi sayur-sayuran dan beberapa lauk ikan. Nasi dibentuk bulat mengerucut sebanyak tujuh, yang juga disebut nasi bulat tujuh atau dalam bahasa Jawa disebut sega golong pitu. Sega golong pitu merupakan simbol gumolonging manah, atau tekad hati yang bulat, utuh, dan sepenuh hati. Orang tua dengan segenap 
hati siap untuk mengadapi proses

persalinan

(Wawancara

Budiyanto, 2018).

Gambar 1. Ibu hamil dalam selamatan mitoni bersama keluarga. (26 Agustus 2017)

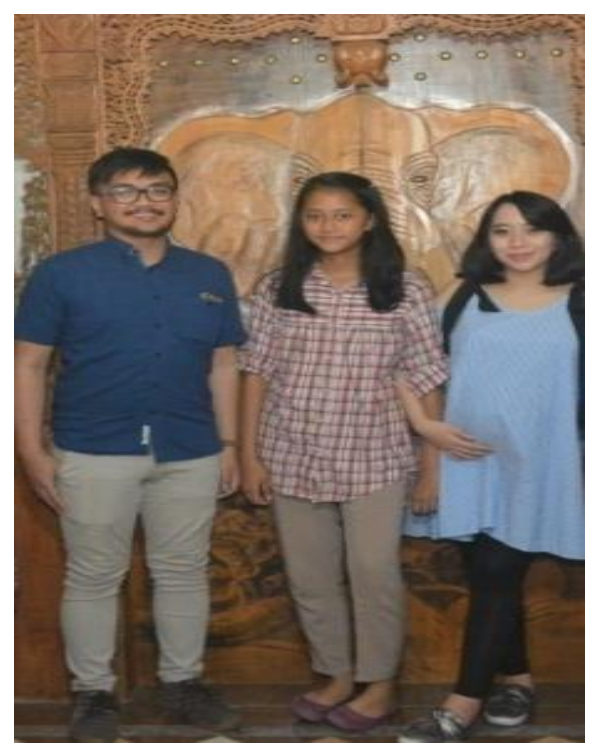

Sumber: Supratigya

Ikan teri dalam sajian tumpeng digoreng dengan tepung dan dibuat menjadi rempeyek. Hal ini melambangkan kehidupan ideal manusia hendaklah selalu rukun dan tidak terpisahkan antara satu dengan yang lainnya (Achmad, 2017: 182).

Jenang procot merupakan simbol pengharapan semoga bayi dapat lahir dengan lancar dan tepat waktu. Arti kata procot, sesuatu yang keluar dengan tiba- tiba dan cepat. Senada dengan itu, Achmad juga menjelaskan bahwa jenang procot dalam mitoni melambangkan keselamatan dan kelancaran ibu hamil yang akan melahirkan (Achmad, 2017: 184).

\section{Pembahasan}

\section{Tahapan Mitoni dalam \\ Perspektif \\ Tindakan}

\section{Interaksionisme Simbolik.}

Interpretasi simbol terjadi dalam ritual mitoni, hal ini dikarenakan dalam setiap tahapan mitoni sarat dengan makna simbol. Makna simbol tersebut merupakan bentuk edukasi non verbal yang mendorong masyarakat Jawa di Tuntang memelihara harmoni sosial. Ritual mitoni masyarakat desa Tuntang dalam perspektif teoritis tindakan interaksionisme simbolik, merupakan suatu bentuk kehidupan sosial.

Nilai Spiritual dalam Tahapan Mitoni Masyarakat Desa Tuntang. 
Jurnal Ilmu Budaya, Vol. 16, No. 1 Agustus Tahun 2019

\section{Nilai spiritual yang \\ terkandung dalam tahapan mitoni \\ di Tuntang ialah sebagai berikut:}

\section{Ngruwat Sukerta}

Ngruwat sukerta atau membuang sial, merupakan nilai spiritual yang terdapat pada tahapan siraman. Ruwatan adalah upacara untuk membebaskan seseorang yang sedang kerasukan setan atau yang sedang diganggu roh jahat (Syuropati, 2015: 166). Ritual ruwatan pada umumnya diyakini oleh masyarakat setempat sebagai tameng atau senjata untuk menghindarkan masyarakat dari berbagai bahaya bencana (Wahidah, 2015: 207). Ruwatan memiliki arti pencerahan batin kepada yang diruwat, dilakukan dengan maksud memutus rantai hukum karma (Mandali, 2010: 117).

Ngruwat sukerta memiliki arti penyucian dari kekotoran batin, agar sifat buruk dari orang tua tidak diturunkan pada anak. Anak dilahirkan dalam kondisi yang suci, sehingga hidupnya dibebaskan dari hal-hal yang buruk. Senada dengan itu, Setiawan menjelaskan bahwa upacara siraman merupakan simbol pernyataan tanda pembersihan diri, baik fisik maupun jiwa (Setiawan, 2015: 45).

Ibu merupakan pengasuh pertama dan utama bagi anak yang masih ada dalam kandungan (Santosa, 2013: 65). Ia dapat merawat anaknya dengan baik dikarenakan telah diadakan penyucian melalui siraman.

\section{Cecawis}

Persiapan atau cecawis merupakan nilai spiritual yang terdapat pada tahapan ganti pakaian atau ganti busana. Orang tua mempersiapkan secara psikologis dan materi untuk menghadapi persalinan. Orang tua, ketika memiliki anak, akan mengalami berbagai suka dan duka, yang dilambangkan dengan tujuh corak kain yang berbeda.

\section{Sembada}


Tahapan ganti pakaian atau ganti busana memiliki nilai spiritual bertanggungjawab atau sembada. Keluarga mengalami keadaan yang serba kecukupan, dalam bahasa Jawa disebut sembada. Kata sembada secara harfiah memiliki makna serba cukup, lengkap, dan kuat. Orang yang sembada bertanggung jawab dan mampu mencukupi kebutuhannya (Syuropati, 2015: 218). Sikap sembada adalah sikap positif manusia yang senantiasa mampu menyelesaikan tugas dan pekerjaannya dengan baik (Achmad, 2017: 11).

\section{Panampi}

Menerima atau dalam bahasa Jawa disebut panampi merupakan nilai spiritual yang terdapat pada tahapan brojolan. Orang tua bersedia menerima kelahiran anaknya apapun jenis kelaminnya, baik laki-laki ataupun perempuan. Penerimaan terhadap kehadiran anak ini menggambarkan spiritualitas batin orang Jawa, yaitu nrima atau "menerima". Hal ini sesuai nasihat luhur Jawa, yaitu: ndarbeni ati segara, atau "memiliki hati seluas samudera." (Sumodiningrat dan Wulandari, 2014: 271-272).

\section{Wilujeng}

Wilujeng atau selamat merupakan nilai spiritual yang terdapat pada tahapan kenduri. Ibu hamil didoakan agar selamat ketika menjalani persalinan. Kata wilujeng juga bisa berarti suatu sapaan yang hangat bernada halus dan juga bermakna selamat (Syuropati, 2015: 260). Geertz, dikutip oleh Wahidah, mengidentifikasi slametan sebagai: (1) "ritual inti" budaya Jawa; (2) ritus animisme yang memiliki tujuan untuk memperkuat solidaritas sosial dan (3) sebagai sebuah upacara yang utama pada suatu desa (Wahidah, 2015: 210). Bahasa Jawa untuk kata selamat ialah selamet. Selamet ini memiliki makna aman dan selamat (Syuropati, 2015: 217). Ritus selametan memiliki 
tujuan untuk memperkuat

solidaritas sosial (Wahidah, 2015:

210).

Ngrumat Bumi

Tahapan siraman $\begin{array}{r}\text { juga } \\ \text { memiliki nilai spiritual }\end{array}$
memelihara alam. Air yang
digunakan untuk siraman
dianjurkan diambil dari tujuh
sumber mata air yang berbeda,
dalam bahasa Jawa disebut tuk
pitu. Manusia perlu menjaga
sumber air di setiap desa supaya
tidak kering. Nilai spiritual
memelihara alam merupakan
suatu upaya orang Jawa untuk
melestarikan alam semesta.

\section{Pitutur}

Tahapan upacara kenduri mitoni memiliki nilai spiritual pitutur artinya nasihat. Pitutur disampaikan oleh ayah, ditujukan kepada anak dan menantunya. Nasihat tersebut berisi bimbingan untuk menolong anak dan menantunya tentang bagaimana kesiapan secara mental, fisik dan spiritual menyambut bayi yang akan lahir.

\section{Rukun}

Orang Jawa memahami bahwa yang disebut rukun apabila dapat makan bersama. Sesuai dengan penjelasan Surbono, kerukunan masyarakat Jawa terjalin dalam aktivitas doa dan makan bersama seluruh warga (Surbono dan Sutiyono, 2018: 48). Nilai spiritual rukun terdapat pada tahapan kenduri. Kenduri mitoni merupakan upacara makan bersama yang menjadi perekat sosial masyarakat desa Tuntang.

\section{Pitulungan}

Manusia selalu membutuhkan orang lain dalam kehidupannya. Hal ini juga menjadi pandangan hidup manusia Jawa. Angka tujuh dalam bahasa Jawa disebut pitu, yang memiliki makna pitulungan atau pertolongan. Itulah sebabnya pada saat selamatan mitoni diadakan identik dengan penggunaan bilangan tujuh. Menurut Budiyanto, kata tujuh dalam bahasa Jawa adalah pitu, berarti 
pitulungan atau pertolongan

(Wawancara Budiyanto, 2018).

Nilai-nilai tersebut dapat digunakan oleh pemimpin agama dalam membina umat untuk meningkatkan harmoni sosial. Nilai ini berfungsi sebagai energi sosial yang positif untuk menyatukan masyarakat desa Tuntang yang beraneka ragam.

\section{Penutup}

Mitoni adalah salah satu cara komunikasi orang Jawa dengan menggunakan simbolsimbol. Nilai-nilai spiritual mitoni merupakan simbolisasi ideologi Jawa yang bersifat eskatologis yang berfungsi untuk memelihara harmoni sosial.

Nilai spiritual yang terkandung dalam tahapan mitoni di Tuntang meliputi; 1). Ngruwat sukerta yang artinya membersihkan hal-hal buruk. 2). Cecawis atau persiapan merupakan persiapan secara psikologis untuk menghadapi persalinan yang rumit. 3). Sembada atau bertanggungjawab.
Anak kelak menjadi manusia yang bertanggung jawab atas kehidupannya. 4). Panampi atau menerima merupakan spiritualitas Jawa yang berkenan menerima perbedaan dengan toleransi. 5). Wilujeng atau selamat artinya suatu permohonan kepada Tuhan agar ibu dan anak diberi keselamatan. 6). Ngrumat Bumi atau memelihara bumi memiliki makna merawat perbedaan dengan sikap toleran dan menghargai sesama manusia yang berbeda. 7). Pitutur atau nasihat kepada orang tua tentang kesiapan secara mental, fisik dan spiritual menyambut bayi yang akan lahir. 8). Rukun merupakan cita-cita hidup orang Jawa. Kerukunan masyarakat terpelihara melalui acara kenduri mitoni. 9). Pitulungan atau pertolongan, artinya manusia adalah makhluk sosial yang selalu membutuhkan pertolongan dari orang lain.

Nilai-nilai tersebut dapat menjadi perekat sosial budaya masyarakat Jawa. Hal ini dikarenakan nilai spiritual 
tersebut dapat diterima oleh masyarakat.

Hasil penelitian ini direkomendasikan bagi pemimpin agama dan tokoh adat untuk menerapkan cara ini, dengan menjadikan mitoni sebagai perekat sosial budaya. Output penelitian ini ialah generasi muda masyarakat Jawa diharapkan memahami teologi kejawen khususnya tentang mitoni.

\section{Daftar Pustaka}

Achmad, S. W. 2017. Filsafat Jawa:menguak filosofi, ajaran, dan laku hidup leluhur Jawa. Yogyakarta: Araska

Adriana, I. (2012). Neloni, Mitoni atau Tingkeban: (Perpaduan antara Tradisi Jawa dan Ritualitas Masyarakat Muslim). JURNAL KARSA, 19(2), 238-247. http://karsa.stainpamekasan.a c.id/index.php/jks/article/vie $\mathrm{w} / 12$

Allen, P. (2015). Diasporic representations of the home culture: case studies from Suriname and New Caledonia. Asian Ethnicity, 16(3), 353-370. https://doi.org/10.1080/1463

1369.2013.853544

Baihaqi, I. (2017). Karakteristik Tradisi Mitoni di Jawa Tengah Sebagai Sebuah Sastra Lisan. Arkhais, 08(2), 136-156.

https://doi.org/https://doi.org /10.21009/ARKHAIS.082.05

Buhori. (2017). Islam dan Tradisi Lokal di Nusantara (Telaah Kritis Terhadap Tradisi Pelet Betteng Pada Masyarakat Madura dalam Perspektif Hukum Islam). Jurnal AlMaslahah, 13(2), 229-246. https://jurnaliainpontianak.or .id/index.php/Almaslahah/art icle/view/926/500.

Dagun, S. M. 2015. Kamus Besar Ilmu Sosial. Jakarta: Lembaga Pengkajian Kebudayaan Nusantara.

Humaeni, Ayatullah. (2015). Ritual, Kepercayaan Lokal dan Identitas Budaya Masyarakat Ciomas Banten. el Harakah, 17(2), 157-181. https://doi.org/http:// dx.doi.org/10.18860/el.v17i2 .3343 .

Jones, P. 2010. Pengantar TeoriTeori Sosial dari Teori Fungsionalisme hingga PostModernisme. Jakarta: Yayasan Pustaka Obor Indonesia.

Kurnialoh, Nasri dan Suharti, S. (2016). Pendidikan Islam 
Berbasis Inklusifisme dalam Kehidupan Multikultur. Jurnal Penelitian, 10(1), 201-232. https://doi.org/10.21043/jupe .v10i1.1337.

Machmudah, U. (2016). Budaya Mitoni:Analisis Nilai-nilai Islam dalam Membangun Semangat Ekonomi. el harakah Jurnal Budaya Islam., 18(2), 185-198. http://dx.doi.org/10.18860/el. v18i2.3682.

Mandali, K. S. 2010. Bawarasa Kawruh Kejawen Ngelmu Urip. Semarang: Yayasan Sekar Jagad.

Marliyana, M., Syah, I., \& Wakidi, W. (2016). Tradisi Mitoni Masyarakat Jawa Di Desa Marga Kaya Kabupaten Lampung Selatan. PESAGI (Jurnal Pendidikan dan Penelitian Sejarah), 4(1). http://jurnal.fkip.unila.ac.id/i ndex.php/PES/article/view/1 0727\%5Cnhttp://jurnal.fkip. unila.ac.id/index.php/PES/art icle/download/10727/pdf_15 8.

Masduki. (2017). Toleransi Di Masyarakat Plural Berbasis Budaya Lokal (Studi Kasus di Desa Klepu Kec. Sooko Kab. Ponorogo). Sosial Budaya, 4(1), 14-22. https://doi.org/10.24014/SB. V14I1.4159.
Mustaqim, M. (2017). Pergeseran Tradisi Mitoni: Persinggungan Antara Budaya Dan Agama. Jurnal Penelitian, 11(1), 119-140. https://doi.org/10.21043/jupe .v11i1.2016.

Nuha, U. (2016). Tradisi Ritual Buka Luwur (Sebuah Media Nilai-nilai Islam dan Sosial Masyarakat Kudus. Jurnal SMART Studi Masyarakat, Religi, dan Tradisi. 02(01), 55-65.

Rifai, M. (2017). Etnografi Komunikasi Ritual Tingkeban Neloni dan Mitoni. Ettisal:Journal of Communication, Vol. 2, 2739.

https://ejournal.unida.gontor. ac.id/index.php/ettisal/search /search.

Risdianawati, L. F., \& Hanif, M. (2015). Sikap Masyarakat Terhadap Pelaksanaan Upacara Kelahiran Adat Jawa Tahun 2009-2014 (studi di desa Bringin Kecamatan Kauman Kabupaten Ponorogo. Jurnal Agastya, 5(1), 30-66. https://doi.org/http://doi.org/ 10.25273/ajsp.v5i01.895.

Saddhono, K., \& Pramestuti, D. (2018). Sekar Macapat Pocung: Study of Religous Values Based On Javanese Local Wisdom. el Harakah, 20(1),

15-32. 
http://dx.doi.org/10.18860/el. v20i1.4724.

Santosa, I. B. 2012. Spiritualisme Jawa Sejarah, Laku, dan Intisari Ajaran. Yogyakarta: Memayu Publishing.

Santosa, I. B. 2013. Manusia Jawa Mencari Kebeningan Hati Menuju Tata Hidup Tata Krama Tata Prilaku. Yogyakarta: Diandra Pustaka Indonesia.

Setiawan, E. (2015). Nilai Religius Tradisi Mitoni dalam Perspektif Budaya Bangsa Secara Islami. alAdalah, 18(1), 39-52. http://digilib.uinsuka.ac.id/3808/1/BAB\%20I, IV,\%20DAFTAR\%20.

Sugiyono. 2017. Metode Penelitian Kualitatif untuk penelitian yang bersifat:eksploratif, enterpretif, interaktif dan konstruktif. Bandung:

Alfabeta.
Sumodiningrat, G dan Wulandari. 2014. Pitutur Luhur Budaya Jawa. Yogyakarta: NARASI

Surbono, W. (2018). Bentuk dan Makna Simbolik Tembang dalam Konteks Upacara Rebo Pungkasan Kembul Sewu Dulur. Jurnal Pustaka Budaya, 5(2), 42-51. https://doi.org/DOI:https://do i.org/10.31849/pb.v5i2.1577

Syuropati, M. A. 2015. Kamus Pintar Kawruh Jawa Daftar Kata, Nama dan Istilah Penting dalam Bahasa, Sastra, dan Budaya Jawa. Yogyakarta: In Azna Books

Wahidah, H. (2015). The Ritual and Mythology of Ruwatan in Mojokerto. Jurnal Religió: Jurnal Studi Agamaagama, 5(September), 207222 